\title{
Radionuclide Techniques for Identifying Vulnerable Plaque
}

The task of science is to stake out the limits of the knowable, and to center consciousness within them. Rudolf Virchow

$\mathbf{T}_{\mathrm{t}}$ by Spagnoli et at 1815 of this issue of The Journal of Nuclear Medicine (1) provides an excellent review of the pathophysiology of atherosclerosis, focusing on the major role of inflammation in the genesis, progression, and symptomatology of the disease. The American Heart Association (2) indicates that the term atherosclerosis comes from 2 Greek words: athero, meaning gruel or paste, and sclerosis, meaning hardening. Although the process was recognized

See page 1800

centuries ago (3), Rudolf Virchow, the 19th-century German pathologist, suggested that inflammation played an important role. An alternative view, espoused by the Austrian pathologist Carl von Rokitansky, suggested a role for blood (especially fibrin) in the pathology of atherosclerosis $(4,5)$. It is now apparent that both of these renowned pathologists were correct: A combination of the "vulnerable plaque" and the "vulnerable patient" contributes to a clinical event. A recent analysis of tissue specimens from autopsies performed by von Rokitansky nearly 2 centuries ago demonstrated CD3-positive cells in early lesions,

Received Aug. 8, 2007; revision accepted Aug. 17, 2007.

For correspondence or reprints contact: $\mathrm{H}$. William Strauss, MD, Memorial Sloan-Kettering Cancer Center, 1275 York Ave., Room S-212, New York, NY 10021

E-mail: straussh@mskcc.org

COPYRIGHT ( 2007 by the Society of Nuclear Medicine, Inc.

DOI: 10.2967/jnumed.107.044651

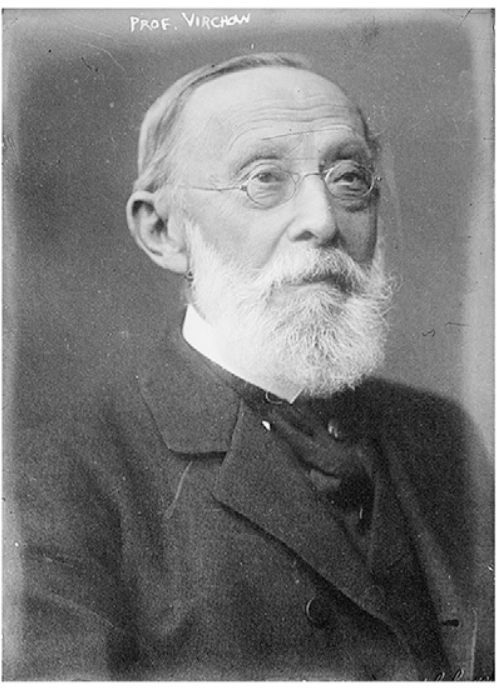

Virchow

suggesting that the role of inflammation in the pathophysiology of atheroma has not changed since early descriptions of the disease. As Spagnoli et al. (1) indicate, inflammation plays a major role in atherosclerosis, especially in the coronary arteries. They also point out that atherosclerosis is a diffuse disease, with multiple plaques capable of causing clinical events, although often only one culprit lesion causes a clinical event. Plaques go through multiple cycles of lipid infiltration, inflammation, progression, and healing. These cycles are associated with the formation of small, clinically silent, nonocclusive thrombi, endogenous thrombolysis, resorption, reendothelialization and, at times, calcification $(6,7)$. This cyclic process is associated with numerous signaling pathways (e.g., integrins, chemokines, angiogenesis, and apoptosis), cell types (e.g., monocytes, macrophages, mast cells, and lymphocytes), and metabolic

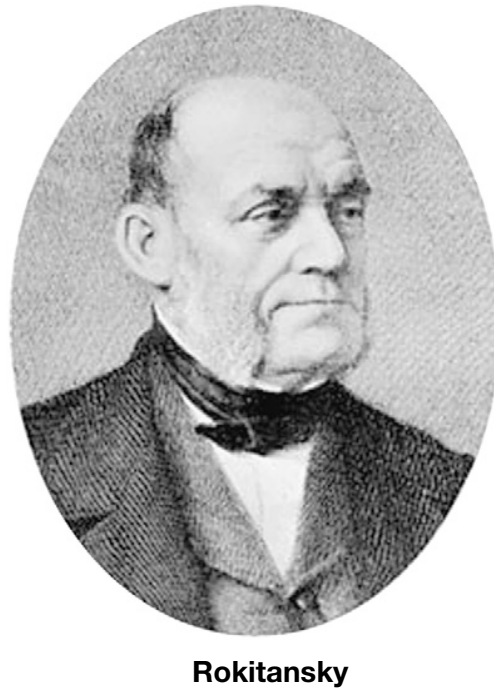

events. Each event offers an opportunity for detection and characterization with radionuclide imaging.

The following is an incomplete list of agents that have been reported to concentrate in experimental or human atheromas and their mechanisms of localization. There are 4 broad categories of radiolabeled agents:

- Lipoproteins $(8,9)$, methylated (10) and oxidized (11) lipoproteins, and antibodies recognizing oxidized low-density lipoprotein $(12,13)$;

- Markers of inflammation: upregulated integrin expression (14), endothelin receptors (15-17), IgG (18), chemoattractant peptide expression $(19,20)$, macrophage metabolism $\left({ }^{18} \mathrm{~F}-\mathrm{FDG}\right)$ (21-25), macrophage function (e.g., phagocytosis (26) and markers of matrix metalloproteinase expression $(27,28)$ ), and extradomain B of fibronectin (29);

- Markers of cell death (e.g., especially of macrophages and smooth 
muscle cells, which can be identified with annexin V (30-32));

- Antibodies recognizing a change in the smooth muscle phenotype $(33,34)$ (the smooth muscle cells found in atheromas are different from normal vascular smooth muscle cells; in normal tissue, the smooth muscle has a contractile phenotype, whereas in plaque, the smooth muscle has a proliferative phenotype; this phenotypic change is accompanied by a change in the markers on the cell surface, allowing identification of these cells with an antibody recognizing this epitope).

The complex, repetitive cycles of atherosclerosis make it difficult to select the most appropriate marker for identifying patients at risk for imminent events. Identifying lipoprotein and oxidized low-density lipoprotein in an atheroma may be useful in identifying the site of an atheroma but is not likely to offer a differential signal between stable and vulnerable lesions. On the other hand, markers of moderate to severe inflammation, such as macrophage metabolism, integrin expression, or chemotactic receptor expression, are more likely to distinguish stable from unstable lesions. There has been substantial clinical interest in ${ }^{18} \mathrm{~F}-\mathrm{FDG}$ imaging of atheromas because it is widely available and there is an infrastructure of evidence about ${ }^{18} \mathrm{~F}-\mathrm{FDG}$ uptake and inflammation (35-37). These facts alone make a compelling argument to investigate ${ }^{18} \mathrm{~F}-\mathrm{FDG}$ as a marker of vulnerable plaque. There would be no waiting for the approval of a "new" drug. In addition, there are preliminary studies demonstrating the reproducibility of carotid ${ }^{18} \mathrm{~F}-\mathrm{FDG}$ uptake over a 2-wk interval (38) and studies in animals and humans demonstrating a reduction in vascular ${ }^{18} \mathrm{~F}$ FDG uptake as a result of drug therapy $(39,40)$. Even with these exciting data, it is clear that vascular ${ }^{18} \mathrm{~F}-\mathrm{FDG}$ imaging needs further development before it achieves its clinical potential. The most important parameters will be patient preparation, standardization of the time of imaging, gated image acquisition, and quantitation of vascular ${ }^{18}$ F-FDG uptake.

To detect ${ }^{18}$ F-FDG uptake in the coronary arteries, there must be essentially no myocardial ${ }^{18} \mathrm{~F}-\mathrm{FDG}$ uptake. Elimination of the uptake typically seen in the myocardium requires either a pharmacologic or a dietary intervention $(41,42)$. Although prolonged fasting has been suggested, there is no definite evidence that this intervention reliably suppresses myocardial uptake (43-45). Further clinical testing is required to develop a method that will eliminate myocardial uptake in all patients.

Although maximum vascular lesion contrast in the carotid arteries appears to occur at $3 \mathrm{~h}(46)$, the majority of uptake usually occurs in the first 60-120 min. Assuming that lesion uptake is fixed by $2 \mathrm{~h}$ after injection, the lesion count rate is reduced by about one third by waiting an additional hour for enhanced contrast before recording the data. Although activity in the blood pool is reduced, there is a marked degradation in image quality at lower count rates. These data make a relatively compelling argument to image patients at about $2 \mathrm{~h}$ after injection.

Cardiac gating is critical for minimizing the motion of the coronary tree. As with coronary CT angiography, the lower the heart rate, the better the result, because the coronary arteries move least during diastole. At a heart rate of 60, a 16-frame gated acquisition should be adequate. The data should be viewed both as a gated acquisition and with extraction of the approximately 4 usable frames at middle to late diastole that have minimal blurring and that can be summed to enhance the count density of the coronary arteries.

With regard to quantitation, at least 4 factors will have to be considered: partial-volume correction with contemporaneous CT, the intensity of uptake in each lesion (maximum standardized uptake value after partial-volume correction), the number of sites in a specific vascular territory that have uptake over a threshold, and the total number of vascular territories with ${ }^{18} \mathrm{~F}-\mathrm{FDG}$ up- take in the coronary arteries and cerebrovascular bed.

The intensity of uptake correlates with the number of macrophages in a lesion (37), which should be a major indicator of lesion severity. The number of sites that have uptake over a threshold is important because there are usually multiple vulnerable plaques $(47,48)$ in each vascular territory. Summing the total number of lesions should provide evidence for risk in a specific patient.

Integrating additional indicators, such as clinical risk, with the imaging score should add to the predictive power of the study. Similarly, integrating information about a vulnerable patient, such as the likelihood of thrombus formation on a specific lesion (49), should add another dimension to the measurement.

Other ${ }^{18} \mathrm{~F}$-labeled tracers, such as ${ }^{18}$ F-labeled Ap4A (50), which may identify other characteristics of a vulnerable lesion, are under investigation. It is clear that molecular and anatomic imaging of vulnerable plaque will use a multimodality and multitracer approach. In the next $10 \mathrm{y}$, it is likely that a comprehensive characterization of the risk of a cardiac event will be developed. This characterization will include the results of vulnerable plaque scoring, serum lipid and inflammatory markers, global and regional perfusion reserve, myocardial ischemia or scar, the presence of endothelial apoptosis (the likely cause of plaque erosion), and the balance of cholinergic and adrenergic receptor expression (as a marker of possible arrhythmia).

An enhanced understanding of the major role of inflammation and the array of radionuclide imaging procedures for localizing the site(s) of these processes suggest that imaging of vascular inflammation will be an important component of patient care in the next decade.

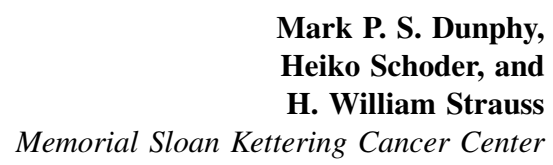
New York, New York 


\section{REFERENCES}

1. Spagnoli LG, Bonanno E, Sangiorgi G, Mauriello A. Role of inflammation in atherosclerosis. $J \mathrm{Nucl}$ Med. 2007;48:1800-1815.

2. American Heart Association. Atherosclerosis. Available at: http://www.americanheart.org/presenter.jhtml? identifier $=4440$. Accessed September 18, 2007.

3. Trevino-Trevino AJ. Atherosclerosis and ischemic heart disease: short historical notes. Gac Med Mex. 1996;132:425-429.

4. Marson P, Zanchin G, Stefanutti C. Some historical considerations on the inflammatory theory of atherosclerosis. Reumatismo. 2004;56:215-219.

5. Mayerl C, Lukasser M, Sedivy R, Niederegger H, Seiler R, Wick G. Atherosclerosis research from past to present: on the track of two pathologists with opposing views, Carl von Rokitansky and Rudolf Virchow. Virchows Arch. 2006;449:96-103.

6. Libby P. The vascular biology of atherosclerosis In: Zipes DP, Libby P, Bonow RO, Braunwald E, eds. Braunwald's Heart Disease. 7th ed. Philadelphia, PA: Elsevier Saunders; 2005:921-937.

7. Schoen FJ, Cotran RS. Blood vessels. In: Cotran RS, Kumar V, Collins T, eds. Robbins' Pathologic Basis of Disease. 6th ed. Philadelphia, PA: W.B. Saunders; 1999:493-542.

8. Lees RS, Lees AM, Strauss HW. External imaging of human atherosclerosis. J Nucl Med. 1983;24: 154-156.

9. Sinzinger H, Bergmann H, Kaliman J, Angelberger P. Imaging of human atherosclerotic lesions using ${ }^{123}$ I-low-density lipoprotein. Eur J Nucl Med. 1986; 12:291-292.

10. Fischman AJ, Lees AM, Lees RS, Barlai-Kovach M, Strauss HW. Accumulation of native and methylated low density lipoproteins by healing rabbit arterial wall. Arteriosclerosis. 1987;7:361-366.

11. Shaish A, Keren G, Chouraqui P, Levkovitz H, Harats D. Imaging of aortic atherosclerotic lesions by ${ }^{125} \mathrm{I}-\mathrm{LDL},{ }^{125} \mathrm{I}$-oxidized-LDL, ${ }^{125} \mathrm{I}-\mathrm{HDL}$ and ${ }^{125}$ I-BSA. Pathobiology. 2001;69:225-229.

12. Tsimikas S, Palinski W, Halpern SE, Yeung DW, Curtiss LK, Witztum JL. Radiolabeled MDA2, an oxidation-specific monoclonal antibody, identifies native atherosclerotic lesions in vivo. $\mathrm{J} \mathrm{Nucl} \mathrm{Cardiol}$. 1999;6:41-53.

13. Tsimikas S, Shortal BP, Witztum JL, Palinski W. In vivo uptake of radiolabeled MDA2, an oxidationspecific monoclonal antibody, provides an accurate measure of atherosclerotic lesions rich in oxidized LDL and is highly sensitive to their regression. Arterioscler Thromb Vasc Biol. 2000;20:689-697.

14. Sadeghi MM, Krassilnikova S, Zhang J, et al Detection of injury-induced vascular remodeling by targeting activated alphavbeta3 integrin in vivo. Circulation. 2004;110:84-90.

15. Prat L, Torres G, Carrió I, et al. Polyclonal ${ }^{111} \mathrm{In}$ IgG, ${ }^{125} \mathrm{I}$-LDL and ${ }^{125}$ I-endothelin-1 accumulation in experimental arterial wall injury. Eur $\mathrm{J} \mathrm{Nucl}$ Med. 1993;20:1141-1145.

16. Tepe G, Duda SH, Meding J, et al. Tc-99m-labeled endothelin derivative for imaging of experimentally induced atherosclerosis. Atherosclerosis. 2001;157: 383-392.

17. Johnstrom P, Rudd JH, Richards HK, et al. Imaging endothelin ET(B) receptors using $\left[{ }^{18} \mathrm{~F}\right]$ BQ3020: in vitro characterization and positron emission tomography (microPET). Exp Biol Med (Maywood). 2006;231:736-740

18. Fischman AJ, Rubin RH, Khaw BA, et al Radionuclide imaging of experimental atherosclerosis with nonspecific polyclonal immunoglobulin G. J Nucl Med. 1989;30:1095-1100.
19. Ohtsuki K, Hayase M, Akashi K, Kopiwoda S Strauss HW. Detection of monocyte chemoattractant protein-1 receptor expression in experimental atherosclerotic lesions: an autoradiographic study. Circulation. 2001;104:203-208.

20. Blankenberg FG, Wen P, Dai M, et al. Detection of early atherosclerosis with radiolabeled monocyte chemoattractant protein-1 in prediabeteic Zucker rats. Pediatr Radiol. 2001;31:827-835.

21. Vallabhajosula S, Fuster V. Atherosclerosis: imag ing techniques and the evolving role of nuclear medicine. J Nucl Med. 1997;38:1788-1796.

22. Tatsumi M, Cohade C, Nakamoto Y, Wahl RL. Fluorodeoxyglucose uptake in the aortic wall at PET/CT: possible finding for active atherosclerosis. Radiology. 2003;229:831-837.

23. Tahara N, Kai H, Yamagishi S, et al. Vascular inflammation evaluated by $\left[{ }^{18} \mathrm{~F}\right]$-fluorodeoxyglucose positron emission tomography is associated with the metabolic syndrome. J Am Coll Cardiol. 2007;49: 1533-1539.

24. Dunphy MP, Freiman A, Larson SM, Strauss HW. Association of vascular ${ }^{18} \mathrm{~F}$-FDG uptake with vascular calcification. J Nucl Med. 2005;46:12781284

25. Zhao Y, Kuge Y, Zhao S, et al. Comparison of ${ }^{99 m} \mathrm{Tc}$-annexin A5 with ${ }^{18} \mathrm{~F}$-FDG for the detection of atherosclerosis in $\mathrm{ApoE}^{-1-}$ mice. Eur J Nucl Med Mol Imaging. April 17, 2007 [Epub ahead of print].

26. Davies JR, Rudd JH, Weissberg PL, Narula J. Radionuclide imaging for the detection of inflammation in vulnerable plaques. $J$ Am Coll Cardiol. 2006;47(8 suppl):C57-C68.

27. Wu YW, Kao HL, Chen MF, et al. Characterization of plaques using ${ }^{18} \mathrm{~F}-\mathrm{FDG} \mathrm{PET} / \mathrm{CT}$ in patients with carotid atherosclerosis and correlation with matrix metalloproteinase-1. J Nucl Med. 2007;48:227-233.

28. Schafers M, Riemann B, Kopka K, et al. Scintigraphic imaging of matrix metalloproteinase activity in the arterial wall in vivo. Circulation. 2004;109:2554-2559.

29. Dietrich T, Perlitz C, Licha K, et al. ED-B fibronectin (ED-B) can be targeted using a novel single chain antibody conjugate and is associated with macrophage accumulation in atherosclerotic lesions. Basic Res Cardiol. 2007;102:298-307.

30. Kolodgie FD, Petrov A, Virmani R, et al. Targeting of apoptotic macrophages and experimental atheroma with radiolabeled annexin $\mathrm{V}$ : a technique with potential for noninvasive imaging of vulnerable plaque. Circulation. 2003;108:3134-3139.

31. Hartung D, Sarai M, Petrov A, et al. Resolution of apoptosis in atherosclerotic plaque by dietary modification and statin therapy. J Nucl Med. 2005; 46:2051-2056.

32. Strauss HW, Mari C, Patt BE, Ghazarossian V. Intravascular radiation detectors for the detection of vulnerable atheroma. J Am Coll Cardiol. 2006; 47(8 suppl):C97-C100.

33. Narula J, Petrov A, Bianchi C, et al. Noninvasive localization of experimental atherosclerotic lesions with mouse/human chimeric Z2D3 F( $\left.\mathrm{ab}^{\prime}\right) 2$ specific for the proliferating smooth muscle cells of human atheroma: imaging with conventional and negative charge-modified antibody fragments. Circulation. 1995;92:474-484.

34. Carrio I, Pieri PL, Narula J, et al. Noninvasive localization of human atherosclerotic lesions with indium 111-labeled monoclonal Z2D3 antibody specific for proliferating smooth muscle cells. J Nucl Cardiol. 1998;5:551-557.

35. Yamada S, Kubota K, Kubota R, Ido T, Tamahashi N. High accumulation of fluorine-18-fluorodeoxy- glucose in turpentine-induced inflammatory tissue. J Nucl Med. 1995;36:1301-1306.

36. Kaim AH, Weber B, Kurrer MO, Gottschalk J, Von Schulthess GK, Buck A. Autoradiographic quantification of ${ }^{18}$ F-FDG uptake in experimental softtissue abscesses in rats. Radiology. 2002;223:446451.

37. Tawakol A, Migrino RQ, Hoffmann U, et al. Noninvasive in vivo measurement of vascular inflammation with F-18 fluorodeoxyglucose positron emission tomography. J Nucl Cardiol. 2005; 12:294-301.

38. Rudd JH, Myers KS, Bansilal S, et al. ${ }^{18}$ Fluorodeoxyglucose positron emission tomography imaging of atherosclerotic plaque inflammation is highly reproducible: implications for atherosclerosis therapy trials. J Am Coll Cardiol. 2007;50: 892-896.

39. Ogawa M, Magata Y, Kato T, et al. Application of ${ }^{18} \mathrm{~F}-\mathrm{FDG}$ PET for monitoring the therapeutic effect of antiinflammatory drugs on stabilization of vulnerable atherosclerotic plaques. J Nucl Med. 2006; 47:1845-1850

40. Tahara N, Kai H, Ishibashi M, et al. Simvastatin attenuates plaque inflammation: evaluation by fluorodeoxyglucose positron emission tomography. J Am Coll Cardiol. 2006;48:1825-1831.

41. Taegtmeyer H, King LM, Jones BE. Energy substrate metabolism, myocardial ischemia, and targets for pharmacotherapy. Am J Cardiol. 1998; $82: 54 \mathrm{~K}-60 \mathrm{~K}$

42. Israel O, Weiler-Sagie M, Rispler S, et al. PET/CT quantitation of the effect of patient-related factors on cardiac ${ }^{18}$ F-FDG uptake. J Nucl Med. 2007; 48:234-239.

43. Fukuchi K, Ohta H, Matsumura K, Ishida Y. Benign variations and incidental abnormalities of myocardial FDG uptake in the fasting state as encountered during routine oncology positron emission tomography studies. Br J Radiol. 2007; 80:3-11.

44. Kaneta T, Hakamatsuka T, Takanami K, et al. Evaluation of the relationship between physiological FDG uptake in the heart and age, blood glucose level, fasting period, and hospitalization. Ann Nucl Med. 2006;20:203-208.

45. de Groot M, Meeuwis AP, Kok PJ, Corstens FH, Oyen WJ. Influence of blood glucose level, age and fasting period on non-pathological FDG uptake in heart and gut. Eur J Nucl Med Mol Imaging. 2005;32:98-101.

46. Rudd JHF, Warburton EA, Fryer TD, et al. Imaging atherosclerotic plaque inflammation with $\left({ }^{18} \mathrm{~F}\right)$-fluorodeoxyglucose positron emission tomography. Circulation. 105:2708-2711.

47. Ohtani T, Ueda Y, Mizote I, et al. Number of yellow plaques detected in a coronary artery is associated with future risk of acute coronary syndrome: detection of vulnerable patients by angioscopy. J Am Coll Cardiol. 2006;47:2194-2200.

48. Libby P. Atherosclerosis: disease biology affecting the coronary vasculature. Am J Cardiol. 2006;98: 3Q-9Q.

49. Langer H, Schonberger T, Bigalke B, Gawaz M. Where is the trace? Molecular imaging of vulnerable atherosclerotic plaques. Semin Thromb Hemost. 2007;33:151-158.

50. Elmaleh DR, Fischman AJ, Tawakol A, et al. Detection of inflamed atherosclerotic lesions with diadenosine-5',5'"-P1,P4-tetraphosphate (Ap4A) and positron-emission tomography. Proc Natl Acad Sci USA. 2006;103:15992-15996. 